\title{
Personal And Work-Related Correlates Of Mental Health In Slovak Women In Higher Education
}

Rosemary Krawczyk, Minnesota State University, Mankato, USA Jon Kalinowski, Minnesota State University, Mankato, USA

\begin{abstract}
Two samples of Slovak women in higher education were surveyed in order to determine the extent to which the personal attributes of locus of control and life satisfaction and work-related attributes of role conflict and ambiguity are related to mental health symptomatology. The personal attribute of external locus of control correlated positively with symptoms of psychological distress. Life satisfaction correlated negatively with mental health. Role conflict and ambiguity each correlated positively with all symptoms of psychological distress. Moderating effects of locus of control and life satisfaction were not found. Results are discussed in relation to findings from similar surveys of U.S. women in higher education and with respect to changes in higher education in post-communist Central and Eastern European countries.
\end{abstract}

Keywords: Women, higher education, Slovakia, mental health

\section{INTRODUCTION}

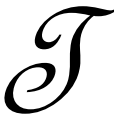

he period since 1989, with the fall of many Communist regimes in eastern and central Europe, may be characterized as one of major social and economic change. The transition to market economies has had an impact on the work and personal lives of individuals living in those countries. Like many changes of this magnitude, the effects are not uniformly positive and those involved will likely experience some degree of stress and related psychological symptoms. Bobak et al. (2006) found the prevalence of depressive symptoms in several eastern European urban areas to be higher than in other European countries. The same study found the prevalence of depressive symptoms in women to be twice that of men in Poland, Russia, and the Czech Republic. Cockerham et al. (2006) also found that women in post-Communist Belarus, Kazakhstan, Russia and Ukraine experienced greater psychological distress than did their male counterparts. For women in Poland and the Czech Republic, more education was associated with less depression. Although the opposite pattern was found among the Russian women studied (Bobek et al., 2006). The mental health benefits of education for women in Poland were found primarily among younger women (Wroblewska, 2002). Relatively little has been written about mental health symptomatology in the post-Communist Slovak Republic. The aim of the present study is to examine mental health variables in relation to specific work-related and personal factors in a sample of Slovak women employed in higher education.

Role conflict and ambiguity are two work-related variables that have been found to be important to the quality of employee experience in the workplace. In a meta-analysis of the correlates of role conflict and ambiguity, Fisher and Gitelson (1983) found a strong correlation between both variables and tension/anxiety. These relationships were moderated, however, by job type, with role conflict correlating positively with tension/anxiety only for professionals. The positive relationship between role ambiguity and tension/anxiety was found only among managers and those in nonprofessional roles. A recent study found role conflict to be directly associated with emotional exhaustion, depression and somatic symptoms, and women showing more depressive and somatic symptoms than men (Pomaki, Supeli \& Verhoeven, 2007). In the present study we expect to find that role conflict and ambiguity reported by Slovak women in higher education will correlate negatively with mental health. 
The personal attribute of locus of control has been shown to be related to mental health symptomatology. People who are more internal, that is, who hold positive beliefs about their ability to control their environment, report less anxiety and depression than those who are more external (Taylor et al., 2000). In a Hungarian sample, low control in work settings was closely related to depressive symptoms and hostility (Kopp et al., 2000). Overall, women feel they have less personal control than do men (Davidson \& Fielden, 1999). A study of employed women found that external locus of control predicted personal distress (Noor, 2002). Although there is some evidence of cultural relativity in measures of locus of control (Smith, Tromenaars \& Dugan, 1995), we predict that there will be a negative relationship between level of externality and mental health symptomatology in the Slovak women in this study.

Additionally, locus of control was found to moderate the influence of work-related attributes on job satisfaction and organizational commitment (Loscocco \& Roschelle, 1991) and between stress and mental health (Parkes, 1994). In fact, locus of control was found to be one of the strongest moderators between stress and mental health (Cohen \& Edwards, 1989). Noor (2002) found locus of control to be a moderating factor in the relationship between work-family conflict and well-being in Malaysian women. We would expect to find a similar effect in the present study.

Life satisfaction, the feeling that one's life is good, is one of three components of subjective well-being. Subjective well-being has been related to an individual's ability to deal effectively with stressful life circumstances (Park, 2004). Negative correlations have been observed between life satisfaction and a variety of psychological symptoms, including depression and anxiety. In addition to direct effects, life satisfaction has been found to moderate the effects of stress on symptoms of psychological distress (Park, 2004; Chioqueta \& Stiles, 2007). The present study will examine the relationship between measured life satisfaction and symptomatology as well as the possible buffering effect of life satisfaction on the relationship between stressful work situations and psychological distress. We predict that life satisfaction and symptomatology will be negatively correlated and that, for individuals with high life satisfaction, the positive relationship between role conflict and ambiguity and distress symptoms will be reduced. The hypotheses in the present study of Slovak women in higher education, then, are:

H1: Role conflict and ambiguity will correlate positively with symptoms of depression, anxiety, hostility, and somatization.

H2: Greater externality will be associated with higher levels of somatization, anxiety, depression, and hostility.

H3: The positive relationship between role conflict and ambiguity and psychological distress symptoms will be moderated by locus of control. High internality will buffer the negative impact of role conflict and ambiguity on mental health.

H4: Life satisfaction will correlate negatively with somatization, anxiety, depression, and hostility.

H5: Life satisfaction will moderate the positive relationship between role conflict and ambiguity and symptoms of psychological distress. High life satisfaction will buffer the negative impact of role conflict and ambiguity on mental health.

\section{METHOD}

\section{Participants}

Two samples of women working in higher education at the University of Bratislava, Slovak Republic were recruited for this study with the help of Dr. Michal Liday and Dr. Helena Sajgalikova, both faculty members at that university. The first sample, drawn in 1996, consisted of 56 women whose mean age was 37.7 years. The mean number of years that these women had been employed in higher education was 12.79 (range 1 to 41 years). The second sample was drawn in 2006. This sample was comprised of 35 women with a mean age of 45.3 years, who had worked in higher education for an average of 18.3 (range 1 to 44 ) years.

\section{Procedures and Instrumentation}

Research data were collected using a questionnaire, Women in Higher Education, which was translated into Slovakian for the purposes of this study. Included in this questionnaire were subscales assessing Role Conflict and 
Ambiguity, Life Satisfaction, Social Orientation (Rotter Internal-External Locus of Control Scale), Personal Orientation (Symptom Checklist 90-R), and sample demographics.

\section{Role Conflict and Ambiguity}

This scale measures the extent to which respondents report experiencing a) conflict between the various role expectations in the workplace and the demands placed on their time, and b) ambiguity about performance expectations. Making up this scale are seven-point, Likert-type items ranging from 1= Definitely NOT TRUE of my job to 7 = Definitely True of my job. Reliability estimates for this scale range from .80 to .82 (Murphy et al., 1988).

\section{Rotter Internal-External Locus of Control Scale}

The 26 item Rotter Scale measures the extent to which respondents attribute life events to either internal or external causes. The scale is scored toward externality, with higher scores indicating a more external locus of control. The Rotter Scale has been found to have moderate to high concurrent validity (Goodman, 1987; Zerega, 1976). Reliability estimates range from .60 to .89 (Goodman, 1987; Rotter, 1966).

\section{Life Satisfaction Index-A (LSI-A)}

The LSI-A measures five facets of life satisfaction: a) zest vs. apathy, b) resolution and fortitude, c) congruence between desired and achieved goals, d) positive self concept, and e) mood tone. The version of the LSIA used in this study consists of 20, five-point Likert-type items with $1=$ strongly disagree and 5= strongly agree The LSI-A correlates moderately with other measures of life satisfaction ( Neugarten et al., 1961). The reliability estimate is .89 (Blackhurst, Brandt \& Kalinowski, 1998).

\section{Symptom Checklist 90-R}

The SCL 90-R is a self-report measure of psychological distress on nine independent symptom dimensions. The version of the SCL 90-R used in the present study measured four of those symptom dimensions, specifically, somatization, anxiety, depression and hostility. This measure presents brief descriptions of symptoms (e.g., "Trembling"). Participants are asked to rate the extent to which each symptom has caused them distress within the last week. Ratings range from 0 ("not at all") to 5 ("extremely). Reliability estimates range from .77 to .90 (Payne, 1985).

\section{RESULTS}

T-test analyses indicated no significant differences between the 1996 and 2006 samples on any of the variables measured. Additionally, a Chow test was run to determine whether the coefficients obtained from the 1996 and 2006 samples were different for each independent variable. The F-test, indicating whether the coefficients were different, was not significant for any of the independent variables. Additionally, year effects were controlled for before pooling by generating a dummy variable in the regression analysis. No year effect was found to exist. Consequently, data were combined for subsequent analyses.

\section{Personal attributes}

Means, ranges and standard deviations for all measured attributes may be found in Table 1. In the 1996 sample, scores on the Rotter Internal-External Locus of Control Scale ranged from 5 to 20, with a mean of 12.03. Life satisfaction scores ranged from 51 to 85 with a mean of 68.20. In 2006, Locus of Control scores ranged from 4 to 22 , with a mean of 12.68 . Life satisfaction scores ranged from 51 to 87 with a mean of 70.08 . 
Table 1

Subscale Means and Standard Deviations

\begin{tabular}{lllll}
\hline & & Range & Mean & Standard Deviation \\
\hline Locus of Control & $(1996)$ & $5-20$ & 12.12 & 3.47 \\
& $(2006)$ & $4-22$ & 12.68 & 4.32 \\
\hline Role Conflict & $(1996)$ & $21-72$ & 52.36 & 11.98 \\
& $(2006)$ & $22-93$ & 48.64 & 9.97 \\
\hline Role Ambiguity & $(1996)$ & $23-64$ & 45.39 & 17.41 \\
& $(2006)$ & $18-89$ & 41.23 & 8.82 \\
\hline Life Satisfaction & $(1996)$ & $51-85$ & 68.20 & 7.94 \\
\hline Somatization & $(2006)$ & $51-87$ & 70.09 & 7.16 \\
& $(1996)$ & $12-42$ & 20.83 & 5.60 \\
\hline Anxiety & $(2006)$ & $12-31$ & 19.83 & 6.84 \\
& $(1996)$ & $10-42$ & 18.10 & 4.99 \\
\hline Depression & $(2006)$ & $10-36$ & 16.42 & 6.89 \\
& $(1996)$ & $12-38$ & 21.91 & 5.95 \\
\hline Hostility & $(2006)$ & $12-31$ & 19.19 & 4.04 \\
& $(1996)$ & $6-24$ & 10.30 & 2.74 \\
\hline Combined Symptom & $(1906)$ & $6-16$ & 9.43 & 21.56 \\
& $(2006)$ & $41-135$ & 70.60 & 16.62 \\
\hline
\end{tabular}

(1996) $\mathrm{N}=55 \quad(2006) \mathrm{N}=36$

Combined sample zero-order correlation coefficients for the personal attributes Locus of Control and Life Satisfaction with Somatization, Anxiety, Depression, Hostility and Combined Symptoms are presented in Table 2. Greater externality of locus of control was significantly related to higher combined symptom scores (p <.01), greater somatization $(\mathrm{p}<.05)$, anxiety $(\mathrm{p}<.05)$ and depression $(\mathrm{p}<.01)$. No significant relationship was found between externality and hostility. Significant negative correlations were found between life satisfaction and combined symptom scores $(\mathrm{p}<.01)$, greater somatization $(\mathrm{p}<.01)$, anxiety $(\mathrm{p}<.01)$, depression $(\mathrm{p}<.01)$ and hostility $(\mathrm{p}<.05)$.

\section{Work-related Attributes}

Means, ranges and standard deviations for the work-related variables of Role Conflict and Role Ambiguity are presented in Table 1. The scores for Role Conflict ranged from 21 to 72, with a mean of 52.36. Role Ambiguity scores ranged from 23 to 64, with a mean of 45.39. In 2006, scores for Role Conflict ranged from 22 to 93 , with a mean of 48.64. Role Ambiguity scores ranged from 18 to 89, with a mean of 41.23.

Table 2

Zero-order Correlations between Personal and Work Variables And Mental Health

\begin{tabular}{lcccc}
\hline & \multicolumn{2}{c}{ Work Variables } & \multicolumn{2}{c}{ Personal Variables } \\
\hline & Role Conflict & Role Ambiguity & Locus of Control & Life Satisfaction \\
\hline Combined Symptom Scale & $.347^{* *}$ & $.252^{*}$ & $.375^{* *}$ & $-.422^{* *}$ \\
Somatization & $.292^{* *}$ & $.243^{*}$ & $.310^{*}$ & $-.359^{* *}$ \\
Anxiety & $.342^{* *}$ & $.287^{* *}$ & $.314^{*}$ & $-.368^{* *}$ \\
Depression & $.259^{*}$ & $.292^{* *}$ & $.434^{* *}$ & $-.448^{* *}$ \\
Hostility & $.331^{* *}$ & $.252^{*}$ & .123 & $-.242^{*}$ \\
\hline
\end{tabular}

$* \mathrm{p}<.05 * * \mathrm{p}<.01$

Combined sample zero-order correlation coefficients for Role Conflict and Role Ambiguity with Somatization, Anxiety, Depression, Hostility and Combined Symptoms are presented in Table 2. Role Conflict correlated significantly with combined symptom scale measures $(\mathrm{p}<.01)$, somatization $(\mathrm{p}<.01)$, anxiety $(\mathrm{p}<.01)$, depression $(\mathrm{p}<.05)$ and hostility $(\mathrm{p}<.01)$. Higher levels of conflict were related to higher symptomatology in all areas. Significant positive correlations were found between Role Ambiguity and combined symptom measure (p < $.05)$, somatization $(\mathrm{p}<.05)$, anxiety $(\mathrm{p}<.01)$, depression $(\mathrm{p}<.01)$ and hostility $(\mathrm{p}<.05)$. Higher levels of role 
ambiguity were associated with higher levels of symptomatology across areas measured.

\section{Regression Analyses}

Included in Tables 3-6 are the hierarchical regression results for testing the moderating effects of both locus of control and life satisfaction on the relationship between role ambiguity, role conflict, and mental health symptomatology. Step one in the tables provide the effect for each of the work related variables with step two providing the test for both independent variables or main effects. The interaction terms for each model were entered in step three after both independent variables were entered. No moderating effects were found for life satisfaction or locus of control. However, step two results indicated the amount of variance that is accounted for with either work variable and locus of control or life satisfaction ranges from $17 \%$ to $23 \%$ with the incremental $\mathrm{R}^{2}$ for locus of control and life satisfaction all being significant.

Table 3

Hierarchical Regression Analysis for Combined Symptoms on Work Related Attributes, Locus of Control(LC) \& Work Attributes x Locus of Control

\begin{tabular}{|c|c|c|c|c|c|c|c|c|c|}
\hline \multirow[b]{2}{*}{ Variable } & \multicolumn{3}{|c|}{ Role Conflict (RC) } & \multicolumn{6}{|c|}{ Role Ambiguity (RA) } \\
\hline & SEB & $\boldsymbol{B}$ & $t$ & Overall F & & SEB & $\boldsymbol{B}$ & $t$ & Overall F \\
\hline \multicolumn{10}{|l|}{ Step 1} \\
\hline Role Conlict & .169 & .347 & $2.723 * *$ & & Role Ambiguity & .205 & .303 & 2.315 & \\
\hline Adjusted $R^{2}$ & \multicolumn{2}{|c|}{$.104 * *$} & & $7.412 * *$ & Adjusted $R^{2}$ & \multicolumn{2}{|c|}{$.092 *$} & & $5.361 *$ \\
\hline \multicolumn{10}{|l|}{ Step 2} \\
\hline Role Conflict & .166 & .277 & $2.213^{*}$ & & Role Ambiguity & .197 & .247 & 1.966 & \\
\hline Locusof Control & .652 & .309 & $2.466^{*}$ & \multirow[b]{2}{*}{$7.094 * *$} & Locusof Control & .651 & .336 & $2.674 *$ & \\
\hline$R^{2}$ Increment & \multicolumn{2}{|l|}{$.09 *$} & & & $R^{2}$ Increment & \multicolumn{2}{|c|}{$.11 * *$} & & $6.566 * *$ \\
\hline \multicolumn{10}{|l|}{ Step 3} \\
\hline Role Conflict & .508 & -.214 & -2.086 & & Role Ambiguity & .595 & -.293 & -.769 & \\
\hline Locusof Control & 2.047 & -.196 & -.498 & & LocusofControl & 2.191 & .271 & -.640 & \\
\hline RCxLC & .04 & .797 & 1.352 & \multirow[b]{2}{*}{$5.413 * *$} & RAxLC & .049 & .896 & 1.501 & \\
\hline $\begin{array}{l}R^{2} \text { Increment } \\
\mathrm{N}=56\end{array}$ & \multicolumn{2}{|l|}{.027} & & & $\begin{array}{l}R^{2} \text { Increment } \\
\mathrm{N}=55\end{array}$ & \multicolumn{2}{|c|}{.034} & & $5.234 * *$ \\
\hline
\end{tabular}

Table 4

Hierarchical Regression Analysis for Combined Symptoms on Work Related Attributes, Life Satisfaction (LS) \& Work Attributes x Life Satisfaction

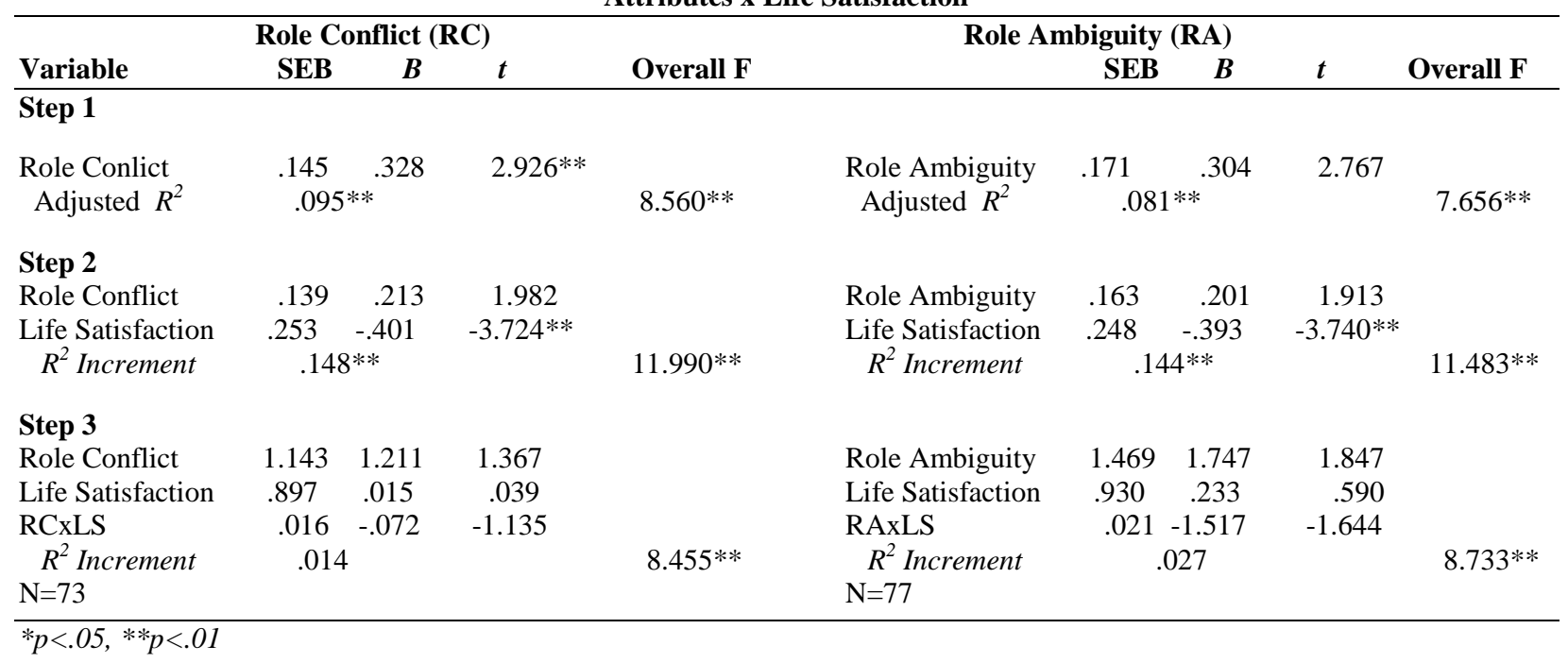




\section{DISCUSSION}

The results of this study provide support for the relationship between the work variables of role conflict and ambiguity and mental health symptomatology. Both work-related variables correlated positively with all dimensions of psychological distress studied. It is clear from previous research that stress results from incompatible role expectations that the individual cannot resolve (Boles, Wood, \& Johnson, 2003). Ongoing stress, in turn, is related to psychological distress.

There has been considerable shifting in role expectations in Central and Eastern European universities in the post-communist period (Smolentseva, 2003; Slantcheva, 2003; Kwiek, 2003). In their 1998 study, Blackhurst, Brandt, and Kalinowski discuss several sources of role conflict for women in higher education. These include working as women in an environment defined by masculine values, the need for women to balance family and work responsibilities and inequities in the workloads of female and male employees. Kwiek (2003) notes that the university reflects a traditional division of gender roles similar to that found within many Polish families. A similar pattern has been observed in Bulgarian universities (Slantcheva, 2003). It appears likely, then, that women in the Slovak Republic may also experience one of the sources of role conflict, a male-defined work environment, outlined by Blackhurst, Brandt, and Kalinowski (1998).

Finding and maintaining a balance between work and family roles and responsibilities is another potential source of role conflict that has been observed in other post-communist Eastern European countries. In the Czech Republic, family involvement is clearly the purview of women, regardless of their employment status (Raabe, 1998). It was noted by van Hoven (2002) that a result of the transition from a socialist state to a market-economy democracy for women in East Germany was the loss of socialist services that supported the family. Issues related to family care have become private problems for women and their families. That this would increase tension between work and family roles is not difficult to imagine. Work-family conflict has been found to result in high stress and lowered psychological well-being (Richardson, Burke \& Mikkelsen, 1999). One would expect that employed Slovak women would experience family-work tension similar to those of women in other post-communist countries. It is not at all surprising, then, to find role conflict and ambiguity among Slovak women in post-communist higher education and that these work-related factors predict the presence of psychological distress.

The personal variables of locus of control and life satisfaction were also found to be related to mental health of Slovak women in higher education. Higher levels of externality of locus of control predicted more symptoms of psychological distress for all areas but hostility. One would expect more externality among women who came of age during a time when communism, with its collectivist orientation, was still in place in Slovakia. Mueller and Thomas (2001) found that an internal locus of control is much less likely to develop in collectivist cultures. The link between locus of control and mental health has been well documented (Taylor et al., 2000). The correlation between external locus of control and depression was particularly strong in these samples which is not surprising given the existing body of literature supporting that relationship (Benassi, Dufour \& Sweeney, 1988).

We did not find, however, that locus of control moderated the effects of role conflict and ambiguity on mental health. We are hesitant to draw any conclusions about this lack of a significant interaction for several reasons. First, Rotter (1975) has pointed out that his I-E scale, the one used in this study, includes items representing a variety of different situations and that it may not be as effective for prediction in specific situations i.e., the workplace. Another concern in the present study is that, in the 1996 sample, nearly half of those responding to the survey failed to respond to all items on the Rotter Scale, rendering those data unusable. This significantly reduced the sample size in the regression analysis. The nonresponses may also have introduced a bias to the remaining data. That is a difficulty when using a forced-choice scale; if neither choice seems applicable, participants simply do not respond. Although we examined the data to see whether there was any pattern to the nonresponses and found nothing, we feel the need to qualify our findings on the influence of locus of control.

The personal variable of life satisfaction was found to predict levels of psychological distress. Higher life satisfaction predicted fewer symptoms of anxiety, depression, hostility and somatization. This pattern is similar to the life satisfaction - mental health relationship found among U. S. women in higher education (Blackhurst, Brandt \& Kalinowski, 1998). Interestingly, however, the overall life satisfaction of Slovak women in higher education was 
considerably lower than that of their counterparts in the U.S. Measured life satisfaction in several eastern European countries has tended to be lower than that in the U.S., with economic factors cited as a strong contributing factor (OECD, 2005). The importance of economic factors on personal well-being is further supported by the finding that depressive symptoms in several eastern European countries were significantly related to self-reported material deprivation (Bobak, et al, 2006). The material deprivation, particularly in comparison to what is likely experienced by U. S. women in higher education, likely contributes to lower life satisfaction among comparably employed Slovak women.

In this study we failed to find a moderating effect of life satisfaction on the relationship between role conflict/ambiguity and symptoms of psychological distress. This result is not consistent with findings of a buffering influence of life satisfaction on psychological distress (Chioqueta \& Stiles, 2007).

We are not prepared to conclude that life satisfaction and locus of control do not, in actuality, moderate the relationship between role conflict/ambiguity and mental health. Even with the pooling of samples, the power of our tests for moderating effects is questionable. With incremental $\mathrm{R}^{2}$ ranging from $1.4 \%$ to $3.4 \%$ we are working with effect sizes that are considered small (Cohen, 1988). If we consider the impact of measurement error on power, even with a reliability coefficient of .80 , the power of our tests is further mitigated by at least $50 \%$. So why report these results when clearly our sample sizes were too small to produce significant tests for moderating effects? If we had been able to produce a sample size greater than 150, the moderating effects may well have approached significance (Aiken \& West, 1991). Aiken and West have also stated that an interaction term explaining $1 \%$ of the variance (squared semi partial) may well be significant when the preceding first order effects (step two of our regression equations) have used up $80 \%$ of the variance in the criterion. A similar interaction would be insignificant if the first order effects only explained $10 \%$ of the variance. As we have stated, our first order effects accounted for between $17 \%$ and $23 \%$ of the criterion variance which further reduces the effect size. While we all are aware of the need for large sample sizes, knowledge of the size of the effects anticipated should drive the size of samples. Researchers should be encouraged to further examine the moderating effects of both locus of control and life satisfaction in conjunction with work related variables with respect to mental health but with larger sample sizes.

This study has limitations that are common to research across countries and languages. We cannot assess the degree to which the translation of our instrument into the Slovak language affects the interpretation of items. Similarly, there is always the danger of scale renorming taking place. Existing scales may be interpreted very differently in varying contexts. Some degree of cultural relativity in the Rotter Locus of Control Scale has been demonstrated (Smith, Trompenaars \& Dugan, 1995). Similarly, Asner-Self et al. (2006) suggest that there may be limited usefulness in subscale measures on the Symptom Checklist-90-Revised across cultures, although the global (combined) scores did appear to maintain validity across cultures.

While this study has provided some information about several factors that relate to psychological distress among women in a post-communist country, this is only one piece of a much larger picture. Mitter (2003) has pointed out the criticality of taking into account regional specificities or the extent to which transformation processes in Central Europe are marked by diversity. The experiences of women in higher education in Slovakia may or may not reflect those of similarly employed women in other post-communist central and eastern European countries. Further research, within other contexts, would allow us to determine both common and unique factors that relate to employed women's mental health. Additionally, the incorporation of gender comparisons would allow us to distinguish those variables that influence psychological well-being that are particular to women.

\section{REFERENCES}

1. Aiken, L. S., \& West, S. G. (1991). Multiple regression: Testing and interpreting interactions. Newbury Park, CA: Sage.

2. Asner-Self, K. K., Schreiber, J. B. \& Marotta, S. A. (2006). A cross-cultural analysis of the Brief Symptom Inventory-18. Cultural Diversity and Ethnic Minority Psychology, 12(2), 367-375.

3. Benassi, V. A., Dufour, C. L. \& Sweeney, P. D. (1988). Is there a relation between locus of control orientation and depression? Journal of Abnormal Psychology, 97(3), 357-367. 
4. $\quad$ Bobak, M., Pikhart, H., Pajak, A., Kubinova, R., Malyutina, S., Sebakova, Topor-Madry, R., Ninkitin, Y. \& Marmot, M. (2006). Depressive symptoms in urban population samples in Russia, Poland and the Czech republic. The British Journal of Psychiatry, 188, 359-365.

5. Blackhurst, A., Brandt, J., \& Kalinowski, J. (1998). Effects of personal and work-related attributes on the organizational commitment and life satisfaction of women student affairs administrators. NASPA Journal, Winter 35, 86-99.

6. Boles, J. S., Wood, J. A. \& Johnson, J. (2003). Interrelationships of role conflict, role ambiguity, and workfamily conflict with different facets of job satisfaction and the moderating effects of gender. Journal of Personal Selling and Sales Management, 23, 99-113.

7. Chioqueta, A. P. \& Stiles, T. C. (2007). The relationship between psychological buffers, hopelessness, and suicidal ideation: Identification of protective factors. Crisis, 28(2), 67-73.

8. Cockerham, W. C., Hinote, B. P., \& Abbott, P. (2006). Psychological distress, gender, and health lifestyles in Belarus, Kazakhstan, Russia, and Ukraine. Social Science \& Medicine, 63, 2381-2394.

9. Cohen, J. (1988). Statistical power analysis for the behavioral sciences (2nd ed.). Hillsdale, NJ: Lawrence Erlbaum.

10. Cohen, S. \& Edwards, J. R. (1989). Personality characteristics as moderators of the relationship between stress and disorder. In R. W. Neufeld (Ed.), Advances in the investigation of psychological stress. (pp. 235283). New York: John Wiley \& Sons.

11. Davidson, M. J. \& Fielden, S. (1999). Stress and the working woman. In G. N. Powell (Ed.), Handbook of gender and work. (pp. 413-426). Thousand Oaks, CA: Sage.

12. Fisher, C. D. \& Gitelson, R. (1983). A meta-analysis of the correlates of role conflict and ambiguity. Journal of Applied Psychology, 68(2), 320-333.

13. Goodman, S.H. (1987). Convergent validity of five locus of control scales. Educational and Psychological Measurement, 47, 743-747.

14. Kopp, M., Skrabski, A. \& Szemak, S. (2000). Psychosocial risk factors, inequality, and self-rated morbidity in a changing society. Social Science \& Medicine, 51, 1351-1361.

15. Kwiek, M., (2003). Academe in transition: Transformations in the Polish academic profession. Higher education, 45, 455-476.

16. Loscocco, K.A., \& Roschelle, A.R. (1991). Influences on the quality of work and nonwork life: Two decades in review. Journal of Vocational Behavior, 39, 182-225.

17. Mitter, W., (2003). A decade of transformation: Educational policies in central and Eastern Europe. International Review of Education, 49, 75-96.

18. Mueller, S. L., \& Thomas, A.S. (2001). Culture and entrepreneurial potential: A nine country study of locus of control and innovativeness. Journal of Business Venturing, 16(1), 51-75.

19. Murphy, C.A., Owen, S.V., \& Gable, R.K. (1988). Causes and consequences of role stress among higher education administrators. Paper presented at the annual meeting of the American Educational Research Association, New Orleans, LA.

20. Neugarten, B.L., Havighurst, R.J., \& Tobin, S.S., (1961). The measurement of life satisfaction. Journal of Gerontology, 16, 134-143.

21. Noor, N. M. (2002). Work-family conflict, locus of control, and women's well-being: Tests of alternative pathways. The Journal of Social Psychology, 142(5), 645-662.

22. OECD (2005) Society at a glance: OECD Social Indicators, OECD, Paris.

23. Park, N. (2004). The role of subjective well-being in positive youth development. ANNALS of AAPSS, 591, 25-39.

24. Parkes, K. R. (1994). Personality and coping as moderators of work stress processes: Models, methods andmeasures. Work \& Stress, 8(2), 110-129.

25. Payne, R. W. (1985). Review of the Symptom Checklist 90. In J. V. Mitchell, Jr. (Ed), The ninth mental measurements yearbook (p. 1326). Lincoln, NE: University of Nebraska Press.

26. Pomaki, G., Supeli, A. \& Verhoeven, C. (2007). Role conflict and health behaviors: Moderating effects on psychological distress and somatic complaints. Psychology \& Health, 22(3), 317-335.

27. Raabe, P. H. (1998). Women, work, and family in the Czech Republic - and comparison with the West. Community, Work \& Family, 1(1), 51-63.

28. Richardson, A. M., Burke, R. J. \& Mikkelsen, A. (1999). Job pressures, orgainizational support, and health among Norwegian women managers. International Journal of Stress Management, 6(3), 167-177. 
29. Rotter, J.B., (1966). Generalized expectancies for internal versus external control of reinforcement. Psychological Monographs: General and Applied, 80(1).

30. Rotter, J. B. (1975). Some problems and misconceptions related to the construct of internal versus external control of reinforcement. Journal of Consulting and Clinical Psychology, 43(1), 56-67.

31. Smolentseva, A., (2003). Challenges to the Russian academic profession. Higher education, 45, 391-424.

32. Slantcheva, S., (2003). The Bulgarian academic profession in transition. Higher education, 45, 425-454.

33. Smith, P. B., Trompenaars, F. \& Dugan, S. (1995). The Rotter Locus of Control Scale in 43 Countries: A test of cultural relativity. International Journal of Psychology, 30 (3), 377-400.

34. Taylor, S. E., Kemeny, M. E., Reed, G. M., Bower, J. E. \& Greenwald, T. (2000). Psychological resources, positive illusions, and health. American Psychologist, 55, 99-109.

35. van Hoven, B., (2002). Experiencing democracy: Women in rural East Germany. Social Politics, 9, 444470 .

36. Wroblewska, W. (2002). Women's health status in Poland in the transition to a market economy. Social Science \& Medicine, 54, 707-726.

37. Zerega, W.D., Jr., (1976). Stability and concurrent validity of the Rotter Internal-External Locus of Control Scale. Educational and Psychological Measurement, 36, 473-475. 


\section{NOTES}

